\title{
Changes in Locomotor Activity and Naloxone-Induced Jumping in Mice Produced by WIN 35,197-2 (Ethylketazocine) and Morphine
}

\author{
Patricia Tepper* and James H. Woods** \\ Departments of Psychology and Pharmacology, University of Michigan, Ann Arbor, Michigan 48109, U.S.A.
}

\begin{abstract}
Acute i.p. administration of morphine or cocaine produced increase in locomotor activity in Swiss-Webster female mice that were maximal at $32-$ $100 \mathrm{mg} / \mathrm{kg}$ for morphine and at $32 \mathrm{mg} / \mathrm{kg}$ for cocaine. WIN 35,197-2 produced dose-dependent decreases in locomotor activity from $3.2-32 \mathrm{mg} / \mathrm{kg}$. Chronic administration of WIN $35,197-2$ led to a $6-10$ fold shift to the right in the locomotor activity decreasing effect of the drug, but WIN35,197-2-tolerant mice retained their sensitivity to the locomotor stimulant effects of morphine and cocaine. Acute administration of WIN 35,197-2 failed to sensitize mice to naloxoneinduced jumping, although morphine did so. Chronic administration of WIN 35,197-2 did lead to sensitization to naloxone, but WIN 35,197-2 was much less efficacious in this regard than morphine. These behavioral effects of WIN 35,197-2 may be helpful in the classification of modes of action of different narcotic agonists.
\end{abstract}

Key words: WIN 35,197-2 - Naloxone-induced jumping - Mice - Locomotor activity - Morphine Cocaine

Evidence has been obtained recently for multiple modes of action of different narcotic agonists. Comparisons have been drawn particularly to differences between the ketazocines (e.g., ketazocine and WIN 35, 197-2, also referred to as ethylketazocine; see Figure 1 for structural formulas) and morphine-like drugs. The keta-

\footnotetext{
* Present address: 1110 Oxford House, Nashville, Tenn. 37212 , U.S.A.

** Address for offprint requests: Dr. James H. Woods, M6322 Medical Science Building I, University of Michigan Medical School, Ann Arbor, Michigan 48109, U.S.A.
}

zocines appear to share many of the actions of cyclazocine, while being virtually devoid of cyclazocine's narcotic antagonist activity (e.g., Kosterlitz and Waterfield, 1975; W. Michne, personal communication). Using in vitro preparations, Lord et al. (1977) demonstrated that a variety of 6,7-benzomorphans, including WIN 35,197-2, are relatively less potent than morphine-like compounds in depressing electrically induced contractions of the vas deferens of the mouse as compared to electrically induced contractions of the ileum of guinea pigs. In addition, the ketazocine-like compounds require larger amounts of naloxone relative to morphine to reverse comparable actions in these preparations (Hutchinson et al., 1975). Gilbert and Martin (1976), using the chronic spinal dog, showed that WIN 35,197-2 had relatively less efficacy than morphine in changing respiratory rate, decreasing body temperature, and altering the skin
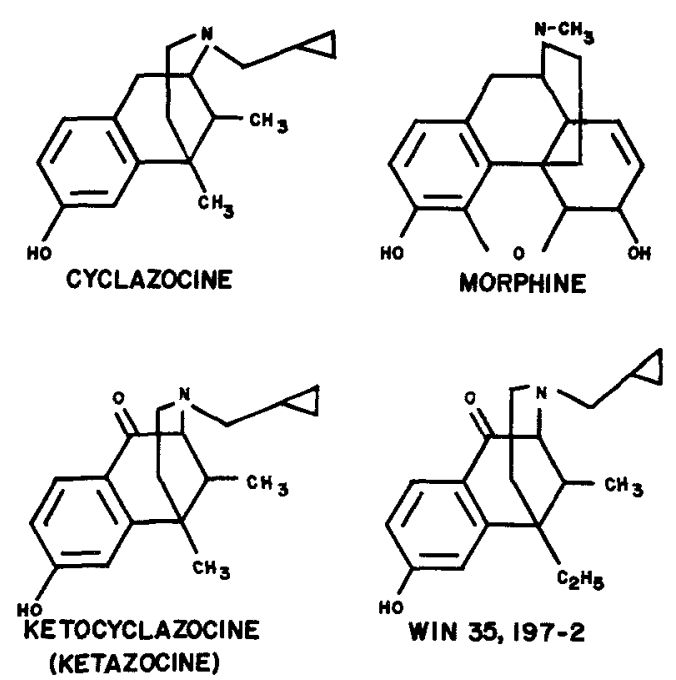

Fig. 1. Structural formulas of cyclazocine, some of its congeners, and morphine 
twitch reflex. Morphine and WIN 35,197-2 had comparable effects in reducing the flexor reflex, while WIN 35,197-2 was a stronger mydriatic. Thus morphine and WIN 35,197-2 have different spectra of acute behavioral and physiological actions in the dog. Following chronic morphine administration, neither ketazocine nor WIN 35,197-2 suppresses specific signs of the morphine abstinence syndrome in the dog (Martin et al., 1976) or the rhesus monkey (H. Swain, personal communication).

The purpose of the present set of experiments was to compare the effects of WIN 35,197-2 and morphine on locomotor activity in the mouse; morphine produces a characteristic increase in mouse locomotor activity (e.g., Goldstein and Sheehan, 1969; Rethy et al., 1971). In addition, we studied WIN 35,197-2 to determine whether tolerance would occur to its effects on locomotor activity and, if so, whether cross tolerance to morphine would be found. We also examined whether naloxone would induce jumping behavior following acute and chronic WIN 35,197-2 administration; naloxone readily induces this jumping following acute morphine administration (e.g. Jacob et al., 1974), and the behavior occurs at a greater rate with naloxone following chronic morphine administration (e.g. Huidobro et al., 1963).

\section{Materials and Methods}

Subjects. The mice used in this study were obtained from Spartan Research Animals, Haslett, Michigan, and were albino females of the Swiss-Webster strain, weighing $25-35 \mathrm{~g}$. The mice were housed in a $30 \times 60 \times 15 \mathrm{~cm}$ group cages in a rodent colony room for $3-7$ days prior to use. They were fed Purina Chow, and water was also freely available; the lights were on from 8 a.m. to 8 p.m. Each mouse was used only once.

Apparatus. The six locomotor activity cages were located in a lightand sound-attenuated chamber. Masking noise and ventilation were provided by an exhaust fan. Each mouse was placed in a separate circular cage $30.5 \mathrm{~cm}$ in diameter and $8 \mathrm{~cm}$ in height. The cages were equipped with two light sources and photocells arranged so that the light beams intersected perpendicularly. Interruption of a beam triggered a pulse former and subsequently registered on a counter; the number of counts in an hour was taken as the measure of locomotor activity.

For observation of jumping behavior, each mouse was placed in a one-gallon glass jar $(15 \mathrm{~cm}$ diameter, $25 \mathrm{~cm}$ high) with the lid turned over and slightly off center. Four to six mice were observed at a time, and jumps were counted by hand on push-button switches attached to pulse counters. A jump was registered when all paws left the floor of the jar. Other activities (e.g., rearing and attempts to 'climb the sides') were excluded. The jumps were counted in a 10-min period immediately following i.p. injection of naloxone.

Procedure. Dose-response curves for locomotor activity in naive mice were obtained for morphine, WIN 35,197-2, and cocaine. For each $1 \mathrm{~h}$ period of locomotor activity measurement, five mice were injected with $0.1 \mathrm{ml} / 10 \mathrm{~g}$ body weight of a drug and one was injected with the same volume of vehicle. Following the injection, the mouse was immediately placed in the locomotor activity cage and, when the six injections were completed, activity was measured for $1 \mathrm{~h}$. After the mice were taken out of the locomotor activity apparatus, they were injected with $16 \mathrm{mg} / \mathrm{kg}$ naloxone and placed in the jars for a 10 -min observation period of jumping behavior.

Chronic administration studies were carried out over 4-day periods. Mice were injected once every $8 \mathrm{~h}$ for 3 days with either morphine or WIN 35,197-2. Injections were given at 08:00, 16:00, and 24:00 with initial injections starting at 08:00. On the 4th day, instead of the routine injection at $8 \mathrm{a} . \mathrm{m}$., the mice received other doses of the same drug or a different drug and observations were made on locomotor activity and naloxone-induced jumping under the same conditions as with acute administration. The group of mice receiving morphine was given $100 \mathrm{mg} / \mathrm{kg}$ every $8 \mathrm{~h}$ and on the 4th day received a variety of morphine doses. Additional mice treated daily with morphine received $100 \mathrm{mg} / \mathrm{kg}$ cocaine on the 4 th day. The mice receiving $10 \mathrm{mg} \mathrm{kg}$ of WIN $35,197-2$ on the first day were injected with $32 \mathrm{mg} / \mathrm{kg}$ of this drug on the second and 3rd days. On the 4th day, half of the group received different doses of WIN 35,197-2; the other half received various doses of morphine. Additional mice from this group were given $100 \mathrm{mg} / \mathrm{kg}$ cocaine.

Mean locomotor activity, mean jumping activity, and their standard errors were determined. Significance of differences between means was evaluated by $t$-tests (two-tailed) and $P$ values are reported.

Drugs. The morphine sulfate, naloxone hydrochloride, and cocaine hydrochloride used in this study were dissolved in $0.9 \%$ saline. WIN 35,197-2, also known as ethylketocylazocine, was dissolved in distilled water with a small amount of lactic acid; sodium bicarbonate was used to bring the $\mathrm{pH}$ of the solution up to about 4 . The benzomorphan was generously supplied by Sterling-Winthrop and the naloxone by Endo Labs.

\section{Results}

Locomotor Activity. WIN 35,197-2 had only a slight effect at $1 \mathrm{mg} / \mathrm{kg}$, but it significantly $(P<0.01)$ depressed locomotor activity at $3.2,10$, and $32 \mathrm{mg} / \mathrm{kg}$ (Fig. 2). At the highest dose, the animals were virtually immobile. At these high doses hyperventilation and splayed hind limbs were prominent signs; when touched, the mice swayed, moved slightly, and then resumed their previous immobile posture. The onset of effects occurred within $5 \mathrm{~min}$ following i.p. injection and at the highest dose the effects continued to be present for over an hour and did not begin to abate until about $75 \mathrm{~min}$ after the injection. Even at $90 \mathrm{~min}$ the mice were quite ataxic and hardly moved. Following chronic administration of 10 and then $32 \mathrm{mg} / \mathrm{kg}$ of WIN 35,197-2, there was a marked, almost tenfold decrease in sensitivity to the locomotor depressant effect of WIN 35,197-2 (Fig. 2). The differences in locomotor activity were statistically reliable $(P<0.01)$ at doses of $3.2 \mathrm{mg} / \mathrm{kg}$ and above. The initial periods of immobility were shorter and the ataxia less severe in mice given WIN 35,197-2 repeatedly.

Morphine induced significant increases in running at all the dose used (Fig. 3); maximal increases occurred at 32 and $100 \mathrm{mg} / \mathrm{kg}$. Following chronic $100 \mathrm{mg} / \mathrm{kg}$ 


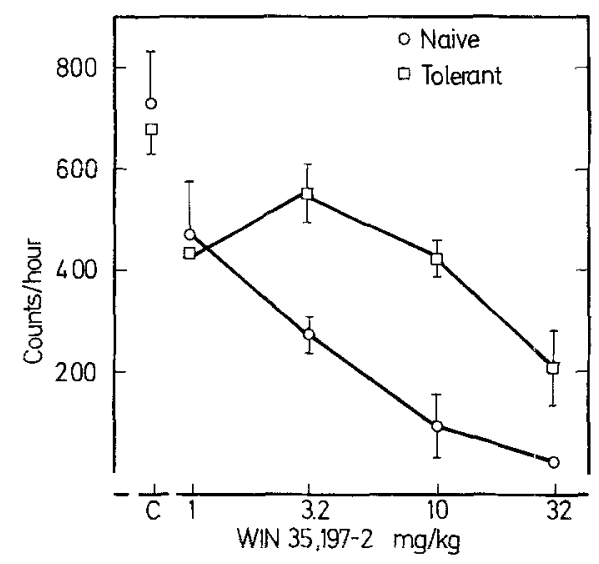

Fig. 2. Locomotor activity changes for $1 \mathrm{~h}$ in mice immediately following i.p. administration of WIN 35,197-2. Open circles: acute administration. Open squares: following chronic administration of 10 and then $32 \mathrm{mg} / \mathrm{kg}$. Points at $C$ on abscissa: vehicle controls for two drug conditions. Data points: average of 5 observations. Brackets: $\pm 1 \mathrm{SE}$

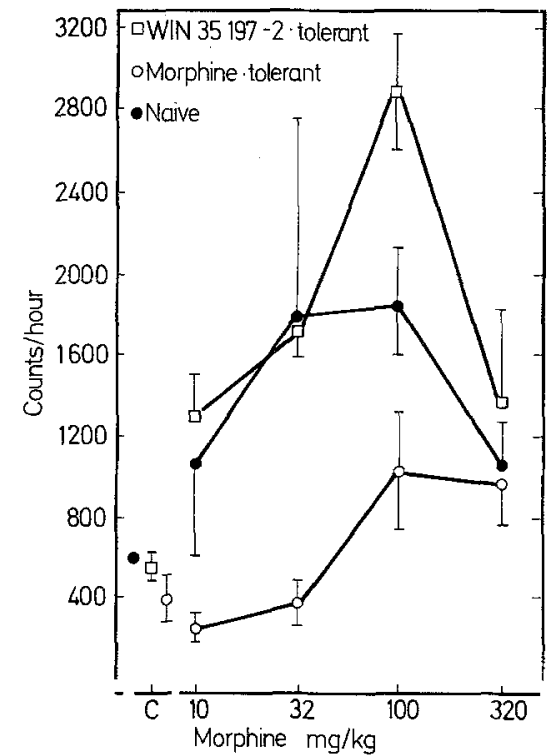

Fig. 3. Locomotor activity changes for $1 \mathrm{~h}$ in mice immediately following i.p. administration of morphine. Closed circles: acute administration. Open circles: following chronic administration of $100 \mathrm{mg} / \mathrm{kg}$ morphine. Open squares: following chronic administration of 10 and then $32 \mathrm{mg} / \mathrm{kg}$ WIN 35,197-2. Data points at $C$ on abscissa : vehicle control observations for three drug conditions. Data points are average of 5 observations. Brackets: $\pm 1 \mathrm{SE}$

morphine administration, there was a decrease in magnitude of the locomotor-increasing effect of morphine. This decrease in sensitivity to morphine was not caused by an impairment of running capacity since chronic-morphine mice given cocaine ran almost as

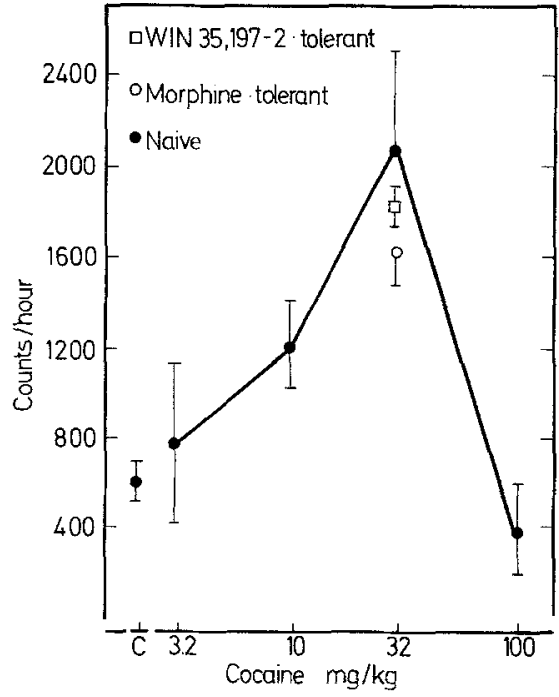

Fig. 4. Locomotor activity for $1 \mathrm{~h}$ in mice immediately following i.p. injection of cocaine. Closed circles: acute administration of cocaine: Open circle: following chronic WIN 35,197-2 administration. Point at $C$ : vehicle control for cocaine (see Fig. 3 for corresponding controls for other groups). Data points: average of 5observations. Brackets: $\pm 1 \mathrm{SE}$

much as naive mice (Fig. 4). Although the cocaine response differed reliably between the naive and morphine-tolerant animals, that difference was far less than the decrement in response to morphine in morphine-tolerant animals.

Mice tolerant to WIN 35,197-2 did not exhibit tolerance to morphine's locomotor stimulant effects (Fig.3). In fact, these animals showed much more running to morphine at $100 \mathrm{mg} / \mathrm{kg}(P<0.05)$ than did naive mice. The mice tolerant to WIN 35,197-2 also retained sensitivity to cocaine (Fig. 4).

Naloxone-Induced Jumping. Naloxone $(16 \mathrm{mg} / \mathrm{kg})$ did not induce jumping in the 10 -minute period following its injection (Fig.5). Mice given various doses of morphine $1 \mathrm{~h}$ previously, on the other hand, jumped a small amount when challenged with this dose of naloxone (Fig. 5; left panel). There was a slight suggestion that maximal morphine priming occurred with the $32 \mathrm{mg} / \mathrm{kg}$ dose. All of the acute doses of WIN 35,197-2 failed to produce jumping following naloxone administration (Fig. 5; right panel).

Chronic administration of morphine exaggerated the effects of acute morphine administration on naloxone-induced jumping. Relatively small amounts of jumping occurred in the absence of acute morphine in mice receiving morphine chronically.

Mice treated chronically with WIN 35,197-2 jumped following naloxone administration (Fig. 5; left panel). These mice showed a significant $(P<0.05)$ 

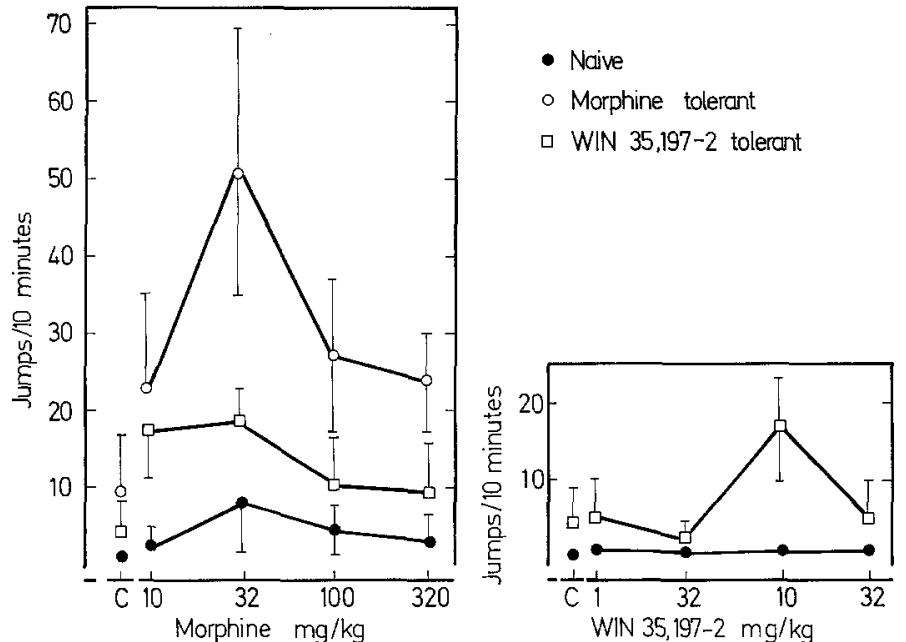

Fig. 5. Naloxone-induced jumping for $10 \mathrm{~min}$ immediately following i.p. injection of $16 \mathrm{mg} / \mathrm{kg}$ of drug. Naloxone injections preceded by vehicle ( $C$ on the abscissae), various doses of morphine (left panell), or WIN 35,197-2 (right panel). Closed circles: acute administration of morphine (left panel) or WIN 35,197-2 (right panel) $1 \mathrm{~h}$ before naloxone. Open circles: following chronic morphine administration of $100 \mathrm{mg} / \mathrm{kg}$. Open squares: following chronic WIN 35,197-2 administration and acute morphine (left panel) or acute WIN 35,197-2 (right panel). Data points: average of 5 observations. Brackets: $\pm 1 \mathrm{SE}$ increase in jumping behavior compared with mice given the same doses $(3.2$ and $10 \mathrm{mg} / \mathrm{kg}$ ) of WIN $35,197-2$ acutely (Fig. 5; right panel). This was also borne out in the mice tolerant to WIN 35,197-2 given morphine $1 \mathrm{~h}$ before naloxone challenge.

\section{Discussion}

WIN 35,197-2, unlike morphine, reduces locomotor activity significantly in the mouse. This finding provides partial support for the supposition of a different mechanism for the two drugs. The reduction in locomotor activity produced by WIN 35,197-2 also differentiates the compound in the mouse from cyclazocine, which induces running that is more resistant to antagonism by naloxone that morphine (e.g., Parker, 1974). The effects of WIN 35,197-2 have been antagonized by naloxone in the vas deferens of the mouse and the guinea-pig ileum (Kosterlitz and Waterfield, 1975) and in operant and other behavioral preparations in the rhesus monkey (Llewellyn and Woods, unpublished observations).

Tolerance to WIN 35,197-2-induced locomotor activity decreases were observed during chronic administration (Fig. 2). The tolerance did not reduce sensitivity to either morphine or cocaine, another indication that WIN 35,197-2 may have a pharmacological specificity not shared with morphine in the mouse. The mechanisms of the WIN 35,197-2 tolerance and the drugs that show cross tolerance with it are interesting topics for future work.

Chronic WIN 35,197-2 administration predisposed mice to jumping when naloxone was administered, an effect shared morphine. Chronic morphine, under these conditions, however, was far more efficacious than
WIN 35,197-2 as a condition for naloxone-induced jumping. Since a common mechanism for this effect is inconsistent with the action of WIN 35,197-2 on locomotor activity, we conclude that naloxone-induced jumping can probably be activated by more than one mechanism. The finding that WIN 35,197-2 primes mice for naloxone-induced jumping should, on the other hand, raise a note of caution for those who would infer a morphine-like action from this behavioral effect in isolation from others. It is perhaps relevant that the characteristics of the withdrawal signs of ketazocine and morphine dependence overlap somewhat in the dog (Martin et al., 1976).

Acknowledgements. This research was supported by the undergraduate Honors program (for the first author) and NIDA Grant DA-00154.

\section{References}

Gilbert, P. E., Martin, W. R.: The effects of morphine- and nalorphine-like drugs in the nondependent, morphinedependent, cyclazocine-dependent chronic spinal dog. J. Pharmacol. Exp. Ther. 198, 66-82 (1976)

Goldstein, A., Sheehan, P.: Tolerance to opioid narcotics. I. Tolerance to the "running fit" caused by levorphanol in the mouse. J. Pharmacol. Exp. Ther. 169, 175-184 (1969)

Huidobro, F., Maggiolo, C., Contreras, E.: Studies on morphine. I. Effect on nalorphine and levallorphan in mice implanted with pellets of morphine. Arch. Int. Pharmacodyn. 144, 196-205 (1963)

Hutchinson, M., Kosterlitz, H. W., Leslie, F. M., Waterfield, A. A., Terenius, L.: Assessment in the guinea-pig ileum and mouse vas deferens of benzomorphans which have strong antinociceptive activity but do not substitute for morphine in the dependent monkey. Br. J. Pharmacol. 55, $541-546$ (1975)

Jacob, J. J. C., Barthelemy, C. D., Tremblay, E. C., Colombel, M. C. $\mathrm{L}$. : Potential usefulness of single-dose acute physical dependence on and tolerance to morphine for the evaluation of narcotic 
antagonists. Adv. Biochem. Psychopharmacol, 8, 299-318 (1974)

Kosterlitz, H. W., Waterfield, A. A.: In vitro models in the study of stucture-activity relationships of narcotic analgesics. Annu. Rev. Pharmacol. 15, 29-47 (1975)

Lord, J. A. H., Waterfield, A. A., Hughes, J., Kosterlitz, H. W.: Endogenous opioid peptides: multiple agonists and receptors. Nature 267, 495-499 (1977)

Martin, W. R., Eades, C. G., Thompson, J. A., Huppler, R. E., Gilbert, P. E.: The effects of morphine- and nalorphine-like drugs in the nondependent and morphine-dependent chronic spinal dog. J. Pharmacol. Exp. Ther. 197, 517-532 (1976)
Parker, R. B.: Mouse locomotor activity: effect of morphine, narcotic antagonists, and the interaction of morphine and narcotic antagonists. Psychopharmacologia (Berl.) 38, 15-23 (1974)

Rethy, C. R., Smith, C. B., Villarreal, J. E.: Effects of narcotic analgesics upon the locomotor activity and brain catecholamine content of the mouse. J. Pharmacol. Exp. Ther. 176, 472-479 (1971)

Received September 20, 1977; Final Version January 13, 1978 